Article

\title{
Soundscape of Catalonia during the first COVID-19 lockdown: Preliminary results from the Sons al Balcó project
}

\author{
Rosa Ma Alsina-Pagès ${ }^{1, *} \mathbb{C}$, Ferran Orga ${ }^{1}\left(\mathbb{D}\right.$, Roger Mallol $^{1, *} \mathbb{D}$, Marc Freixes ${ }^{1}\left(\mathbb{D}\right.$, Xavier Baño $^{2}$ and \\ Maria Foraster ${ }^{3}$ (i) \\ 1 Grup de Recerca en Tecnologies Mèdia (GTM), La Salle-URL, C/Quatre Camins, 30, 08022 Barcelona (Spain); \\ 2 Research and Transference Office, La Salle-URL, C/Sant Joan Baptista de La Salle, 42, 08022 Barcelona \\ (Spain); \\ 3 ISGlobal, Parc de Recerca Biomèdica de Barcelona (PRBB). Doctor Aiguader, 88, 08003 Barcelona (Spain) \\ * Correspondence: rosamaria.alsina@salle.url.edu, roger.mallol@salle.url.edu; Tel.: +34-93-2902425
}

Version December 28, 2020 submitted to Journal Not Specified

1 Abstract: Environmental noise affects the health and wellbeing of millions of people in Europe.

2 Some of the health effects of noise exposure include new cases of ischemic heart disease, chronic

3 annoyance, sleep disturbance and premature death. Our home soundscape, which involves negative

4 (i.e. noise) but also positive sounds (i.e. restorative sounds), changed drastically during the first

5 COVID-19 lockdown. In this context, the Sons al Balcó project is aimed at studying the effect that the

- first lockdown due to the COVID-19 pandemic has caused on the perception of both positive and

7 negative sounds in Catalonia. The hypothesis is that the decrease in outdoor noise, accompanied by

8 a rise of a more positive soundscape would have a positive impact on the degree of annoyance in

- the population, increasing wellbeing. We performed a socio-acoustic survey targeting all the citizens 
changed drastically [6,7] due to the decrease of the activities usually happening in the street. All the noise [8] associated with regular activities outdoors became almost nonexistent. Noise from traffic [9-12], railway noise, port noise [13], airport noise [14] and leisure-related noise [15] were substantially reduced in most of the analyzed cities [16-18], and even in quiet residential areas [19]. Nevertheless, everything seems to come back to normal after the harder episodes of the pandemic, and most of the cities around Europe have come back to their original noise levels in the street [20], maybe losing the opportunity to improve the noise impact on people.

In our project 'Sons al Balcó'[21] we aim to study the effect of the lockdown due to the COVID-19 pandemic caused on the perception of the street noise in Catalonia by means of a Citizen Science proposal. Other similar projects have been conducted in the United Kingdom [22], Italy [23-25] in New York City [26] even worldwide with the goal of registering the exceptional soundscape conditions in all the cities [27]. The starting hypothesis is that noise coming from outdoor (road traffic, railway, plane, and leisure noise), decreased by the lockdown, could be associated with a higher well-being of people.

This paper is structured as follows. Section 2 describes briefly the methodology followed to collect the participatory samples from volunteers. Section 3 describes the preliminary results of the questionnaires and finally, Section 4 reflects the conclusions of this preliminary evaluation of the opinions of the volunteers.

\section{Methods}

During the COVID-19 lockdown, we performed a socio-acoustic digital participatory survey implemented in LimeSurvey [28] and distributed through the social media and press to all citizens of Catalonia. The survey included questions about socio-demographics, the quality of the residential soundscape and the individual positive and negative perception of noise experienced from home before and during the lockdown. Furthermore, the survey allowed participants to upload videos of their residential soundscapes and to characterize several types of sounds sources appearing in the video. The sound source categories that can be marked by the user include: car traffic, trains, airplanes, industry, construction, commercial activities, leisure, neighbours, pets, birds, water-related sounds and vegetation. The survey was implemented using the LimeSurvey platform [28]. This platform does not only allow for the creation of online question-and-answer surveys with a wide variety of response formats, but their source code is also available so to be deployed in your own server. Specifically, we contracted an Amazon EC2 cloud computing instance running a Bitnami Stack for Limesurvey 4.2.3-0 on Ubuntu 16.04.6 LTS. See [21] for more details about the survey conducted.

\section{Results and Discussion}

In total, 365 volunteers from 132 different locations completed the questionnaire and uploaded their video. As a result, we depicted the first soundscape of Catalonia during the COVID-19 lockdown.

How would you describe the sound environment of your home?

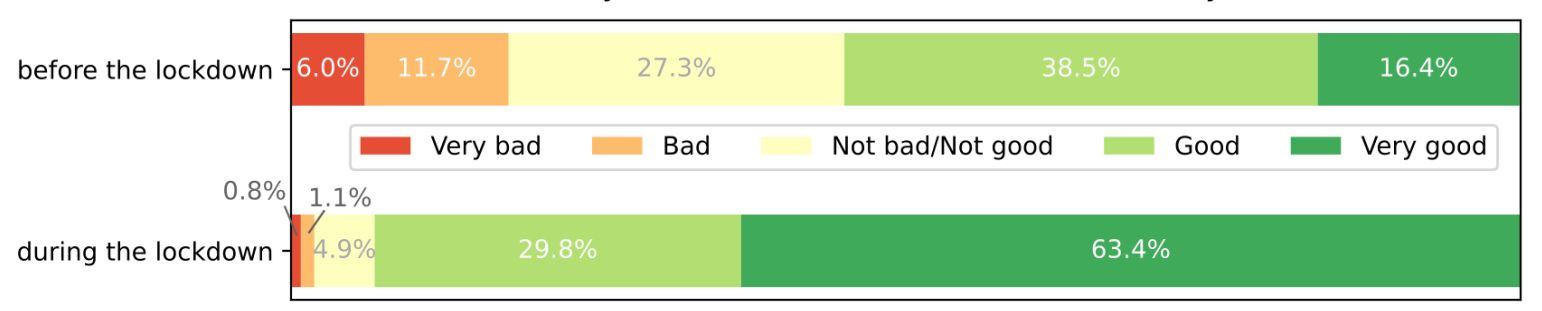

Figure 1. Overall assessment of the sound environment before and during the lockdown.

As we can observe in Figure 1, the $16.4 \%$ of the respondents found their sound environment "Very good" before the lockdown. Notably, the proportion of respondents who found their sound environment "Very good" during the lockdown was $63.4 \%$. The difference in the "Good" category was not as large as in the "Very good" category. Before the lockdown, the proportion of respondents who 
considered their sound environment "Good" was 38.5\%, in comparison with the $29.8 \%$ of respondents who considered that their sound environment was "Good" during the lockdown. Finally, we also found a large difference in the "Not bad/No good" category. 27.3\% of the respondents found their sound environment "Not bad/Not good" before the lockdown. However, the proportion of respondents who found their sound environment "Not bad/Not good" during the lockdown was 4.9\%. For the remaining categories, the difference before and during the lockdown was similar as in the "Good" category (range of the difference between 5\%-10\% approximately).

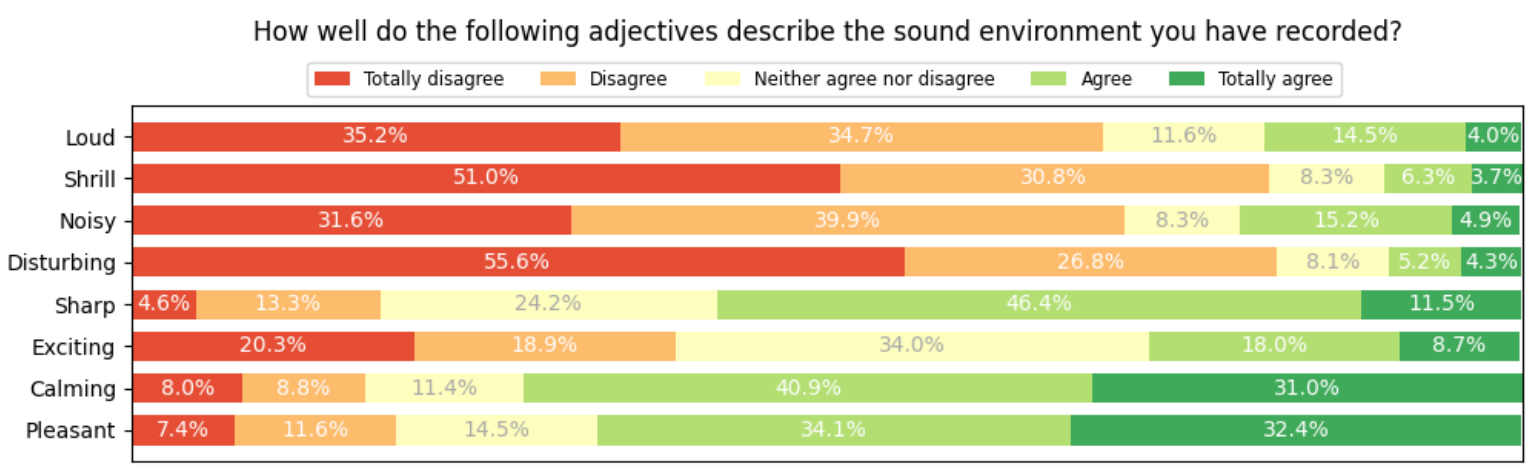

Figure 2. Descriptive assessment of the sounds present in the recordings during the lockdown: Adjectives

Table 1. Descriptive assessment of the sounds present in the recordings during the lockdown: Types of sound sources.

\begin{tabular}{cc}
\hline Sound Source & \% of presence \\
\hline Road traffic & $54.9 \%$ \\
Train & $1.6 \%$ \\
Plane & $1.1 \%$ \\
Industry & $1.1 \%$ \\
Works & $11.7 \%$ \\
Commercial activities & $5.5 \%$ \\
Leisure activities & $7.9 \%$ \\
Neighbours & $47.3 \%$ \\
Pets & $11.5 \%$ \\
Birds & $73.8 \%$ \\
Water & $6.3 \%$ \\
Vegetation & $25.1 \%$ \\
\hline
\end{tabular}

Focusing now in Figure 2, on average, $76.4 \%$ of the respondents did not identify the sounds present in the video recording either as "Loud", "Shrill", "Noisy" or "Disturbing", considering the two categories "Totally in disagreement" and "In disagreement" together. Conversely, $65.5 \%$ of the respondents on average were either "In agreement" or "In total agreement" when identifying the sounds present in the video recordings either as "Sharp", "Calming", or "Pleasant".

On the other hand, and following the results shown in Table 1, when we asked volunteers to identify the types of sounds present in the video recorders, the most present type of sound was the one coming from birds (73.8\%), followed by cars (54.9\%), and neighbours (47.3\%). "Water", "Vegetation", and "Birds" were "not unpleasant at all" according to the $100 \%, 98.9 \%$, and $92.6 \%$ of the respondents (Figure 3). In these cases, the annoyance was the same before and during the lockdown according to $87.0 \%, 80.4 \%$, and $63.7 \%$, respectively (Figure 4 ). Interestingly, $11.9 \%$ of the respondents found the sound from "Road Traffic" "not unpleasant at all". However, when asked more deeply about the pleasance of this sound (Figure 4$), 66.7 \%(n=27)$ of the respondents who found this sound "not unpleasant at all" found it "totally unpleasant" in this second analysis. 


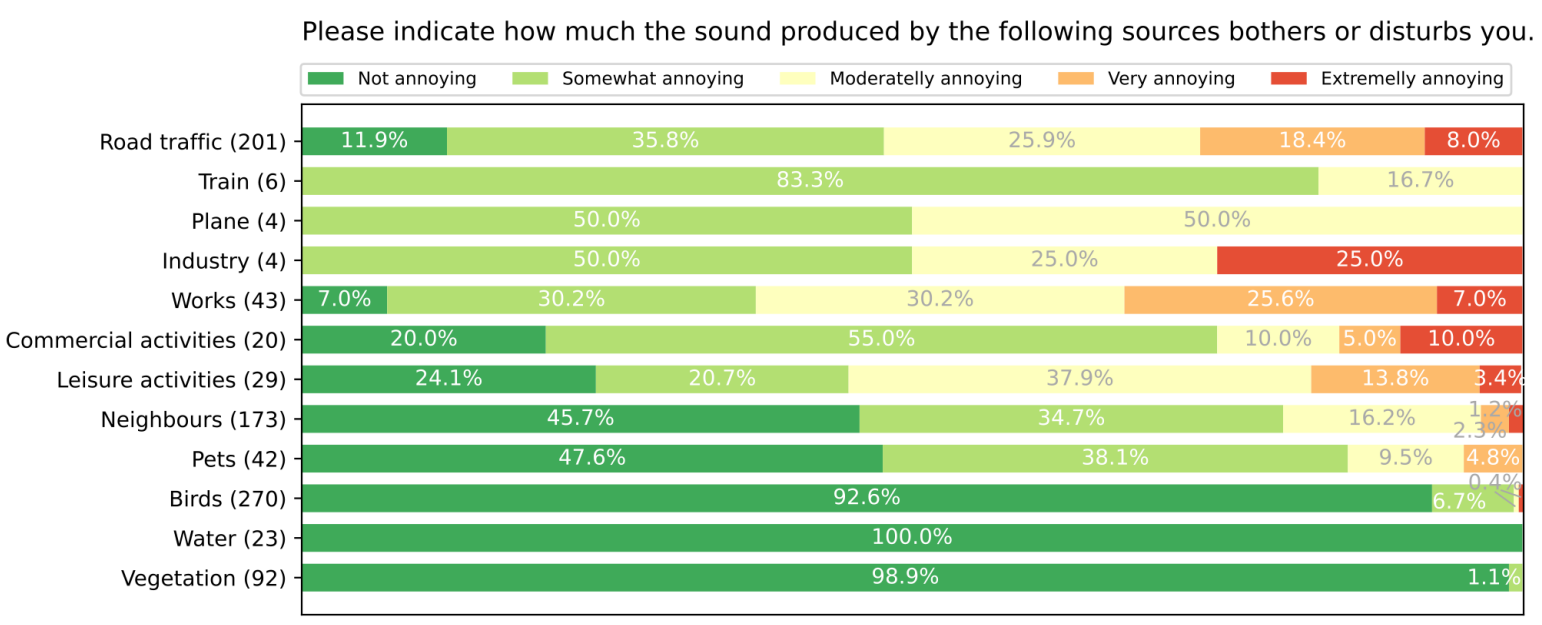

Figure 3. Assessment of the annoyance of the sources present in the recordings during the lockdown

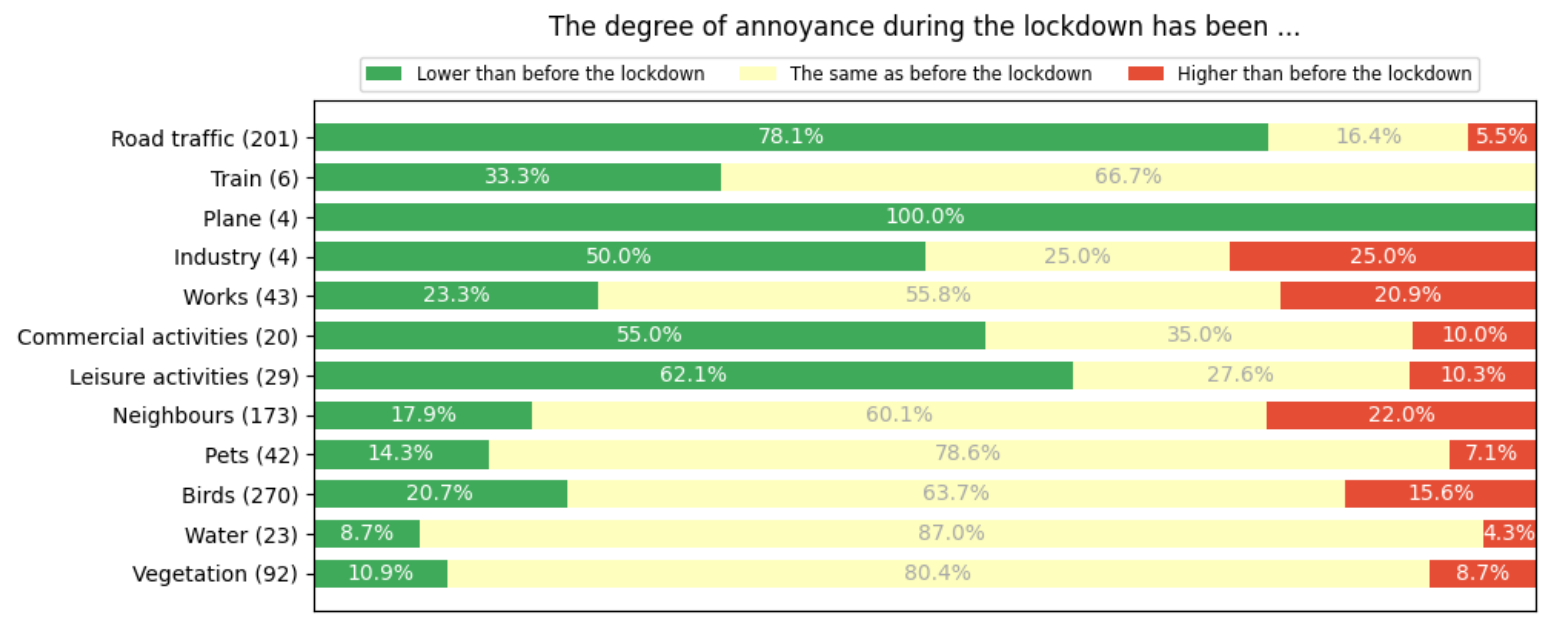

Figure 4. Comparison of the annoyance before and during the lockdown

At this point in the analysis, it is necessary to contrast the subjective results presented here, obtained by means of the questionnaires, with the objective data that can be measured over the uploaded videos. The search for all the acoustic events in the registers (all that the questionnaire ask for), the evaluation of their impact in terms of equivalent level $L_{A e q}$, and the dependence of this equivalent level with that of the background noise will give us valuable information to compare with the subjective answers. Also the processing of the images of the videos will provide us with data about the homes environment, which are also key in understanding the perception of sound by citizens.

\section{Conclusions and Future Work}

This research presents the preliminary results of the questionnaires answered by citizens in the framework of the project 'Sons al Balcó'. The preliminary results presented here show that the volunteers perception of the soundscape has improved during the confinement, and that the typically most annoying noise in urban environments (road traffic, plane noise, industry, commercial activities, etc) is lower during the lockdown than before the lockdown.

The dynamics and results of the project have aroused the interest and has become an active participation of different social agents of the Catalan territory. This allows us to place this work as a starting point for future research activities - maintaining the project objectives - involving other knowledge areas such as education, health, environment, and even culture and citizenship. With the aim of enabling high social impact by means of the results and the scientific dissemination, we will promote collaborative research where social entities, research groups from other disciplines and 
volunteer citizens will be active agents, in order to design and conduct future collecting campaigns, results evaluation and proposals generation.

Future work after this preliminary results will allow us to perform a comparison between both objective (sound and image) and subjective (questionnaires) measures, focusing on the types of noise and sound evaluated, in order to compare the objective metrics $-S N R, L_{A e q}$, by sound, and buildings and trees by image - to the perceptions of the citizens described in the questionnaires, and published in this work.

Author Contributions: RMAP conducted the recording campaign design, planning of the paper, writing and reviewing of the entire paper, and the conceptualization of the project. FO conducted the dissemination and education derivatives from the project Sons al Balcó. RM conducted the results analysis from the project. MF prepared the setup for all the tests from project. $\mathrm{XB}$ conducted the design of the innovation strategy and citizen science communication strategy for the project. MF set the noise and health framework and questionnaire design, wrote and reviewed parts of the paper and conceptualized the project.

Funding: The research that led to this contribution has been conducted thanks to funding from Secretaria d'Universitats i Recerca from the Departament d'Empresa i Coneixement (Generalitat de Catalunya) and Universitat Ramon Llull, under the grant 2020-URL-Proj-054 (Rosa Ma Alsina-Pagès).

Acknowledgments: The authors would like to thank all the participants of this first data collection campaign. The authors would also like to thank the Communications Departments of La Salle - URL and ISGlobal for their support in the dissemination. We would also like to thank Albert Cuesta for his article in Diari Ara, program "El Balcó" from Cadena SER Catalunya for the interview to RMAP, ACUSTICAT conference for giving us some time to talk about the project, and finally, "Via Lliure" from RAC1 for the interview to RMAP and MF. All the media helped us to disseminate the project and collect more data for our project.

Conflicts of Interest: The authors declare no conflict of interest.

\section{Abbreviations}

The following abbreviations are used in this manuscript:

$L_{\text {Aeq }} \quad$ Equivalent Level

UN United Nations

WHO World Health Organisation

\section{References}

1. WHO/Europe I Noise - Data and statistics. Www.euro.who.int/en/health-topics/environment-andhealth/noise/data-and-statistics. Accessed: 2020/09/06.

2. Blanes, N.; Fons, J.; Houthuijs, D.; Swart, W.; de la Maza, M.; Ramos, M.; Castell, N.; van Kempen, E. Noise in Europe 2017: Updated Assessment. European Topic Centre on Air Pollution and Climate Change Mitigation (ETC/ACM): Bilthoven, The Netherlands 2017.

3. Guski, R.; Schreckenberg, D.; Schuemer, R. WHO environmental noise guidelines for the European region: A systematic review on environmental noise and annoyance. International journal of environmental research and public health 2017, 14, 1539 .

4. Jee, Y. WHO International Health Regulations Emergency Committee for the COVID-19 outbreak. Epidemiology and health 2020, 42.

5. Aletta, F.; Osborn, D. The COVID-19 global challenge and its implications for the environment-what we are learning. UCL Open Environment 2020.

6. Aletta, F.; Oberman, T.; Mitchell, A.; Tong, H.; Kang, J. Assessing the changing urban sound environment during the COVID-19 lockdown period using short-term acoustic measurements. Noise Mapping 2020, 7, 123-134.

7. Basu, B.; Murphy, E.; Molter, A.; Basu, A.S.; Sannigrahi, S.; Belmonte, M.; Pilla, F. Effect of COVID-19 on noise pollution change in Dublin, Ireland. arXiv preprint arXiv:2008.08993 2020.

8. Asensio, C.; Aumond, P.; Can, A.; Gascó, L.; Lercher, P.; Wunderli, J.M.; Lavandier, C.; de Arcas, G.; Ribeiro, C.; Muñoz, P.; others. A Taxonomy Proposal for the Assessment of the Changes in Soundscape Resulting from the COVID-19 Lockdown. International Journal of Environmental Research and Public Health 2020, 17, 4205. 
9. Aletta, F.; Brinchi, S.; Carrese, S.; Gemma, A.; Guattari, C.; Mannini, L.; Patella, S.M. Analysing urban traffic volumes and mapping noise emissions in Rome (Italy) in the context of containment measures for the COVID-19 disease. Noise Mapping 2020, 7, 114-122.

10. Alsina-Pagès, R.M.; Alías, F.; Bellucci, P.; Cartolano, P.P.; Coppa, I.; Peruzzi, L.; Bisceglie, A.; Zambon, G. Noise at the time of COVID 19: The impact in some areas in Rome and Milan, Italy. Noise Mapping 2020, 7, 248-264.

11. Benocci, R.; Roman, H.E.; Confalonieri, C.; Zambon, G. Investigation on clusters stability in DYNAMAP's monitoring network during Covid-19 outbreak. Noise Mapping 2020, 7, 276-286.

12. Munoz, P.; Vincent, B.; Domergue, C.; Gissinger, V.; Guillot, S.; Halbwachs, Y.; Janillon, V. Lockdown during COVID-19 pandemic: impact on road traffic noise and on the perception of sound environment in France. Noise Mapping 2020, 7, 287-302.

13. Čurovič, L.; Jeram, S.; Murovec, J.; Novaković, T.; Rupnik, K.; Prezelj, J. Impact of COVID-19 on environmental noise emitted from the port. Science of The Total Environment 2020, p. 144147.

14. Vogiatzis, K.; Zafiropoulou, V.; Gerolymatou, G.; Dimitriou, D.; Halkias, B.; Papadimitriou, A.; Konstantinidis, A. The noise climate at the time of SARS-CoV-2 VIRUS/COVID-19 disease in Athens-Greece: The case of Athens International Airport and the Athens Ring Road (Attiki Odos). Noise Mapping 2020, 7, 154-170.

15. De Lauro, E.; Falanga, M.; Lalli, L.T. The soundscape of the Trevi fountain in Covid-19 silence. Noise Mapping 2020, 7, 212-222.

16. Asensio, C.; Pavón, I.; de Arcas, G. Changes in noise levels in the city of Madrid during COVID-19 lockdown in 2020. The Journal of the Acoustical Society of America 2020, 148, 1748-1755.

17. Montano, W.; Gushiken, E. Lima soundscape before confinement and during curfew. Airplane flights suppressions because of Peruvian lockdown. JASA 2020, 148, 1824-1830.

18. Bartalucci, C.; Borchi, F.; Carfagni, M. Noise monitoring in Monza (Italy) during COVID-19 pandemic by means of the smart network of sensors developed in the LIFE MONZA project. Noise Mapping 2020, 7, 199-211.

19. Sakagami, K. A note on the acoustic environment in a usually quiet residential area after the 'state of emergency'declaration due to COVID-19 pandemic in Japan was lifted: supplementary survey results in post-emergency situations. Noise Mapping 2020, 7, 192-198.

20. Noise returns to Europe after COVID quiet interlude. https://www.politico.eu/article/noise-returns-toeurope-after-covid-quiet-interlude/amp/?_twitter_impression=true. Accessed: 2020/12/28.

21. Alsina-Pagès, R.M.; Orga, F.; Mallol, R.; Freixes, M.; Baño, X.; Foraster, M. Sons al balcó: Soundscape Map of the Confinement in Catalonia. Engineering Proceedings. Multidisciplinary Digital Publishing Institute, 2020, Vol. 2, p. 77.

22. COVID-19: The Quiet Project-Call for Measurements. www.ioa.org.uk/news/covid-19-quiet-project\%E2\%80\%93-call-measurements. Accessed: 2019-09-20.

23. Grande Partecipazione all'iniziativa AIA di caratterizzazione dei Livelli Sonori Durante l'emergenza da Coronavirus. acustica-aia.it/grande-partecipazione-alliniziativa-aia-di-caratterizzazione-dei-livellisonori-durante-lemergenza-da-coronavirus/. Accessed: 2020-09-27.

24. Locate Your Sound-Paesaggi Sonori Italiani Covid19. locateyoursound.com/en/. Accessed: 2019-09-20. 25. Scienzia sul Balcone. comunicazione.cnr.it/evento/254/scienzasulbalcone-misuriamo-il-rumore-intornoa-noi. Accessed: 2019-10-19.

26. The Coronavirus Quieted City Noise. Listen to What's Left. www.nytimes.com/interactive/2020/05/22/ upshot/coronavirus-quiet-city-noise.html?smid=li-share. Accessed: 2020/09/06.

27. Sounds from the Global Covid-19 Lockdown. citiesandmemory.com/covid19-sounds/. Accessed: 2019-09-20.

28. LimeSurvey online survey tool. https://www.limesurvey.org/en/. accessed on 2020-10-12.

(C) 2020 by the authors. Submitted to Journal Not Specified for possible open access publication under the terms and conditions of the Creative Commons Attribution (CC BY) license (http://creativecommons.org/licenses/by/4.0/). 